\title{
A pre-hospital emergency anaesthesia pre-procedure checklist
}

R Mackenzie*1,2, J French ${ }^{1,3}$, S Lewis ${ }^{1,3}$ and A Steel ${ }^{1,4}$

Address: ${ }^{1}$ Magpas Emergency Medical Charity, St Ives, Cambridgeshire, UK, ${ }^{2}$ Senior Lecturer and Honorary Consultant in Emergency Medicine, University Hospitals of Leicester, Leicester, UK, ${ }^{3}$ Specialist Registrar in Emergency Medicine, Eastern Deanery, UK and ${ }^{4}$ Faculty of Pre-hospital Care Training Fellow and Specialist Registrar in Anaesthesia, Eastern Deanery, UK

Email: R Mackenzie* - Rod.Mackenzie@uhl-tr.nhs.uk

* Corresponding author

from Scandinavian Update on Trauma, Resuscitation and Emergency Medicine 2009

Stavanger, Norway. $23-25$ April 2009

Published: 28 August 2009

Scandinavian Journal of Trauma, Resuscitation and Emergency Medicine 2009, 1 7(Suppl 3):O26 doi:10.1 I86/I757-724I-17-S3-O26

This abstract is available from: http://www.sjtrem.com/content/I7/S3/O26

(c) 2009 Mackenzie et al; licensee BioMed Central Ltd.

\section{Introduction}

Pre-hospital emergency anaesthesia (PHEA) is a high-risk activity. Recent guidelines suggest that providers consider using pre-procedure checklists [1]. We applied the principles of checklist development and design to our PHEA practice, developed a pre-anaesthetic checklist and introduced it to our service.

\section{Methods}

An expert group of physicians and paramedics within our service considered:

- Safety critical events (delays, errors or complications associated with PHEA).

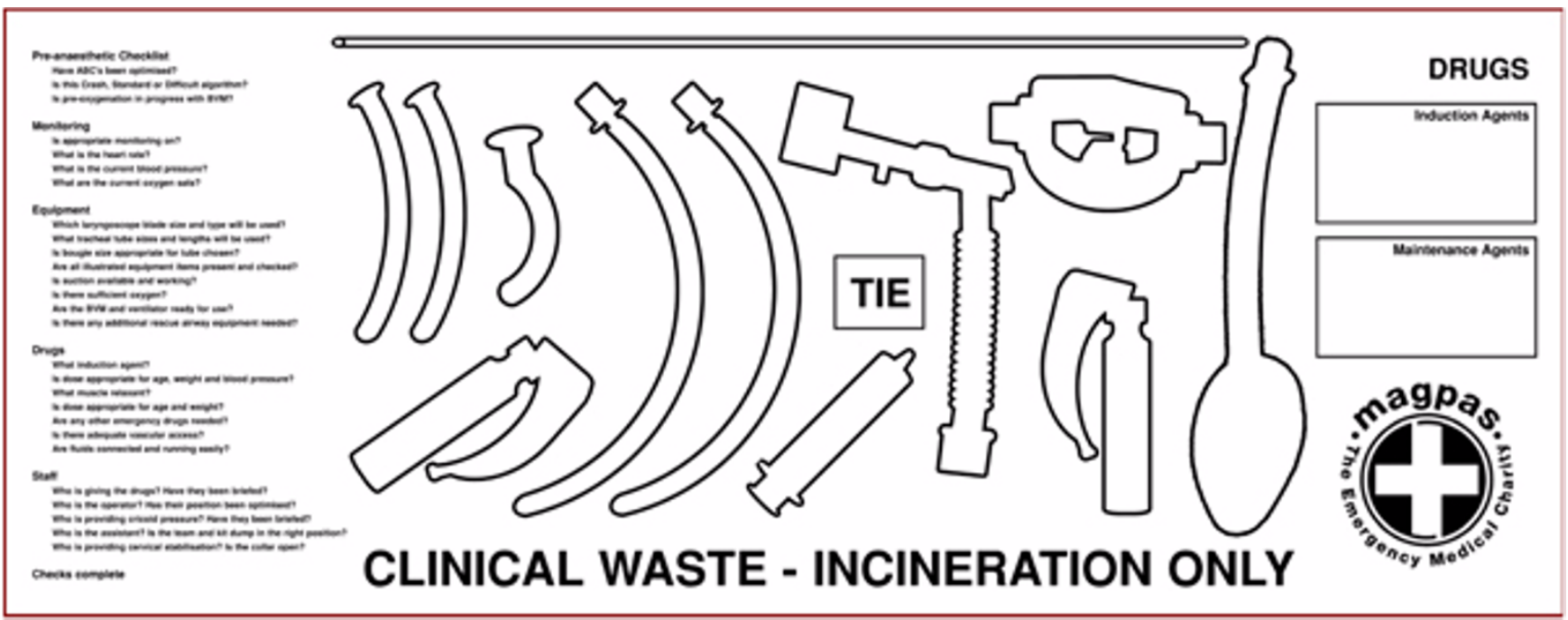

Figure I

PHEA Checklist (full size version will be displayed). 


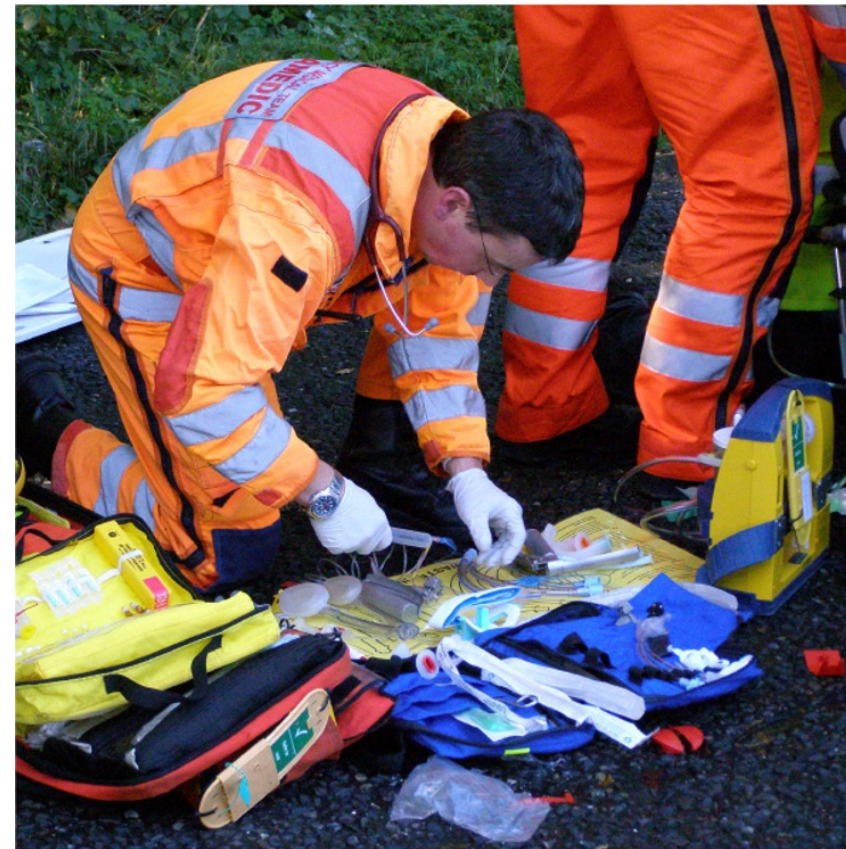

Figure 2

Use of the PHEA checklist (video of checklist in use will be displayed).

- Published guidelines available at the time [2].

- The operational context (i.e. the environment, case mix and clinical practice within the service).

- Criteria for effective checklists (e.g. simplicity, readability).

The group drafted a checklist and tested it in simulated PHEA scenarios. A second version was produced and introduced on our PHEA training programme. Following positive feedback and improved performance with simulated patients [3], we introduced the checklist into our operational service.

\section{Results}

The checklist is printed on a large yellow clinical waste bag and incorporates a written challenge-response checklist and an equipment template (Figure 1). Acceptance of the checklist within the service has been universal and no adverse consequences in terms of time to complete the checklist or other delays to treatment have been observed. Conversely, users have reported that it fulfils its role as an aide memoire and focuses them on pre-induction tasks, processes or equipment items that are safety critical (Figure 2).

\section{Conclusion}

Strandardised pre-procedure checklists reduce the risk of error. They structure complex procedures, improve team dynamics, trap errors associated with human factors (e.g. memory lapses due to task overload) and identify equipment problems [4]. We consider pre-anaesthesia checklists to be essential to the safety of PHEA and recommend that all PHEA providers implement them. We propose a collaborative multi-centre quantitative study if the impact of checklists along the lines of the recently published Safe Surgery Saves Lives campaign [5].

\section{References}

I. Association of Anaesthetists of Great Britain and Ireland: Prehospital anaesthesia. AAGBI; London; 2008.

2. Mackenzie R, Lockey DJ: Pre-hospital Anaesthesia. J R Army Med Corps 200I, 147:322-34.

3. Batchelder AJ, Steel A, Mackenzie R, Hormis AP, Daniels TS, Holding $\mathrm{N}$ : Simulation as a tool to improve the safety of pre-hospital anaesthesia - a pilot study. Anaesthesia 2009 in press.

4. Hales B, Terblanche M, Fowler R, Sibbald W: Development of medical checklists for improved quality of patient care. Int J Qual Health Care 2008, 20:22-30.

5. Safe Surgery Saves Lives Study Group: A surgical safety checklist to reduce morbidity and mortality in a global population. $N$ Engl J Med 2009, 360:491-9.

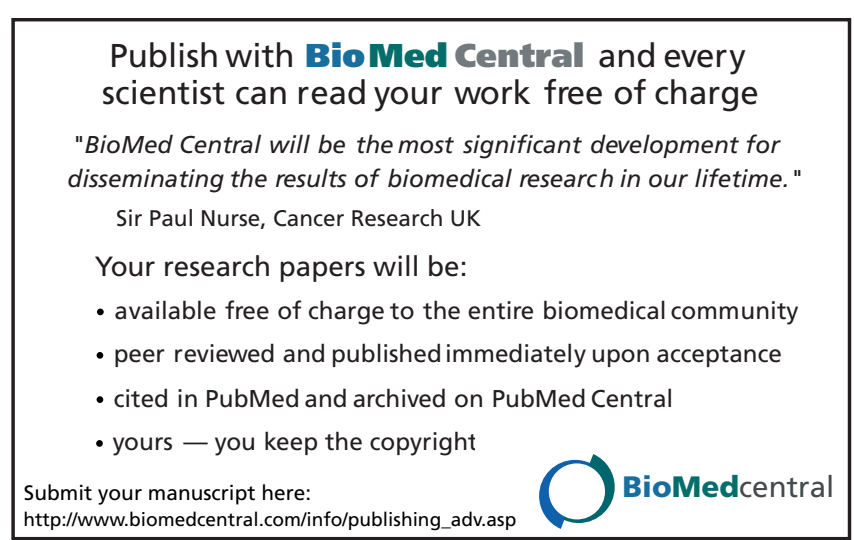

